\title{
Management of Anesthesia and Complications in Pulmonary Endarterectomy Operations
}

Etik Kurul Onayı: Hastanemizin Etik Kurul onayı alınmıştır (2021/403). Çıkar Çatışması: Çıkar çatışması bulunmamaktadır.

Finansal Destek: Yoktur

Hasta Onamı: Hastalardan yazılı onam alınmıştır.
Ethics Committee Approval: The approval of our hospital's Ethics Committee was obtained (2021/403).

Conflict of Interest: There is no conflict of interest.

Funding: None.

Informed Consent: Written informed consent was obtained from all patients.-

Cite as: Erkılınç A, Karaca Baysal P. Pulmoner endarterektomi ameliyatlarında anestezi ve komplikasyonların yönetimi. GKDA Derg. 2021;27(2):139-46.

Öz

Amaç: Kronik tromboembolik pulmoner hipertansiyon pulmoner vasküler yatakta meydana gelen obstrüksiyonlara bağlı gelişen kronik progresif bir hastalıktır. PEA ise; pulmoner arterdeki tromboembolik materyalin etkilenen damar yapılarından eksize edilerek yapıldığı kronik tromboembolik pulmoner hipertansiyon tanımlanmıs cerrahi yöntemidir. Amacımız merkezimizde gerçekleştirilen PEA ameliyatlarındaki anestezi yönetimini ve komplikasyonlar karşısındaki yaklaşımlarımızı paylaşmaktır.

Yöntem: 2017-2020 Haziran ayları içerisinde yapılan 200 tane PEA olgusunun verileri retrospektif olarak incelendi. Hastaların demografik verileri, preopretif solunum fonksiyon testleri, kardiyak kateterizasyon bulguları, peroperatif kardiyak output ölçüm değerleri, aortik kros klemp süreleri, ekstübasyon süreleri, yoğun bakım kalış süreleri, hastane yatış süreleri ve gelişen komplikasyonlar kaydedildi.

Bulgular: Hasta yaşlarının ortalama değeri 50.8, kadın/erkek oranı ise 108/92'dir. Hastaların indüksiyon sonrası yapılan termodilüsyon ölçümlerinde KO, PVR ve mPAP ortalama değerleri sırasıyla $4.4 \mathrm{l} / \mathrm{min}, 594 \mathrm{dyn} / \mathrm{s} / \mathrm{cm}^{-5}, 40 \mathrm{mmHg}$ olarak saptanmıştır. Sternum kapatıldıktan sonra yapılan ölçümler ise yine aynı sırayla $6 \mathrm{l} / \mathrm{min}, 241 \mathrm{dyn} / \mathrm{s} / \mathrm{cm}^{-5}$ ve $28 \mathrm{mmHg}$ olarak belirtilmiștir. Hastaların yoğun bakım yatış süresi 4 gündür. Hasta grubumuzda \%21 oranında rezidüel pulmoner hipertansiyon, \%10 oranında reperfüzyon pulmoner ödem ve \%4 oranında ise pulmoner kanama olmuştur.

Sonuç: PEA cerrahisinde dünyada deneyimli merkez sayısı oldukça azdır. PEA cerrahisi anestezi yönetimi ve komplikasyonlarının tedavisi oldukça zordur. Bu nedenle PEA cerrahisi deneyimli merkezlerde uygulanmalıdır.

Anahtar kelimeler: açık kalp cerrahisi, kronik tromboembolik pulmoner hipertansiyon, pulmoner endarterektomi

\section{ABSTRACT}

Objective: Chronic thromboembolic pulmonary hypertension is a chronic progressive disease developing obstruction ocurring in pulmonary vascular bed. Pulmonary endarterectomy is the surgical procedure described in the management of chronic pulmonary hypertension which excises, and removes the obstructing thromboembolic material from the affected vascular structures. Our aim is to share our approaches to the management of anesthesia and complications in pulomanry endarterectomy operations performed in our center.

Methods: The data of 200 PEA cases conducted in June 2017-2020 were retrospectively analyzed. The demographic data of the patients, preoperative pulmonary function tests, cardiac catheterization findings, peroperative cardiac output measurement values, aortic cross clamp, extubation, intensive care unit, and hospital stay times and complications were recorded. Results: Average age of the patients' ages was 50.8 years, and female/male ratio was 108/92. In the thermodilution measurements of the patients after induction, mean values of CO, PVR and mPAP were determined as $4.4 \mathrm{l} / \mathrm{min}, 594 \mathrm{dyn} / \mathrm{s} / \mathrm{cm}^{-5}, 40 \mathrm{mmHg}$, respectively. The corresponding measurements made after the sternal closure were stated as $6 \mathrm{I} / \mathrm{min}, 241$ $d y \mathrm{n} / \mathrm{s} / \mathrm{cm}^{-5}$ and $28 \mathrm{mmHg}$, respectively. The patients were hospitalized in the intensive care unit for 4 days. In our patient group residual pulmonary hypertension occurred in 21\%, reperfusion pulmonary edema in $10 \%$ and pulmonary bleeding in $4 \%$ of the cases.

Conclusion: Only a very few centers in the world are experienced in PEA surgery. Anesthesia management and treatment of the complications of PEA surgery are quite difficult. Therefore, PEA surgery shl be performed in experienced centers.

Keywords: open heart surgery, chronic thromboembolic pulmonary hypertension, pulmonary endarterectomy

(c) Telif hakkı Göğüs Kalp Damar Anestezi ve Yoğun Bakım Derneği'ne aittir. Logos Tıp Yayıncılık tarafindan yayınlanmaktadır. Bu dergide yayınlanan bütün makaleler Creative Commons Atff-Gayri Ticari 4.0 Uluslararası Lisansı ile lisanslanmıştır.
Received/Geliș: 09.02.2021

Accepted/Kabul: 12.05.2021

Published Online/Online yayın: 03.06.2021

P. Karaca Baysal 0000-0002-5187-8679 SBÜ Kartal Koşuyolu Y.i.E.A.H Anestezi ve Reanimasyon Bölümü istanbul - Türkiye

SBÜ Kartal Koşuyolu Y.i..E.A.H Anestezi ve Reanimasyon Bölümü

İstanbul - Türkiye

dratakan72@yahoo.com ORCiD: 0000-0002-8736-6085

Istanbul - Türkiye




\section{Giriş}

Kronik tromboembolik pulmoner hipertansiyon (KTEPH) pulmoner vasküler yatakta meydana gelen obstrüksiyonlara bağlı gelişen kronik progresif bir hastalıktır. Pulmoner hipertansiyon nedenleri arasında cerrahi tedavi ile düzeltilebilen tek patolojidir ${ }^{[1-3]}$.

Pulmoner endarterektomi (PEA) ise; pulmoner arterdeki tromboembolik materyalin etkilenen damar yapılarından eksize edilerek yapıldığı KTEPH'in tanımlanmış cerrahi yöntemidir ${ }^{[2-3]}$.

KTEPH olgularındaki hastalar, değişen derecelerde sağ ventrikül yetmezliği, paradoksal interventriküler septum hareketi, triküspit yetmezliği, hepatik konjesyon ve düşük kardiyak indeks değerleri ne sahip olabilirler [2]. Kardiyopulmoner baypas (KPB) sırasında gerçekleştirilen derin hipotermi, total sirkülatuar arrest (TSA), peroperatif dönemde gelişebilecek rezidüel pulmoner hipertansiyon, pulmoner kanama ve reperfüzyona bağlı pulmoner ödem gibi klinik durumlar göz önüne alındığında PEA cerrahisinde anestezi yönetimi hemodinamik stabilitenin ve peroperatif gaz değişiminin optimum düzeylerde sağlanması açısından oldukça zordur.

Bu çalışmadaki amacımız, merkezimizde gerçekleştirilen PEA ameliyatlarındaki anestezi yönetimini ve komplikasyonlar karşısındaki yaklaşımlarımızı paylaşmaktır.

\section{GEREÇ ve YÖNTEM}

Hastanemizde etik kurul komitesi tarafından 2021/1/403 No.lu etik kurul onayı alındıktan sonra 2017-2020 haziran ayları içerisinde yapılan toplam 200 tane PEA olgusunun verileri retrospektif olarak incelendi. Veriler hasta kayıtlarından elde edildi. Hastaların demografik verileri, preoperatif solunum fonksiyon testleri (SFT), kardiyak kateterizasyon bulguları, peroperatif kardiyak output (KO) ölçüm değerleri, aortik kros klemp süreleri (AKK), KPB süreleri, ekstübasyon süreleri, yoğun bakım kalış süreleri, hastane yatış süreleri ve gelişen komplikasyonlar kaydedildi.

\section{Anestezik Prosedür}

\section{Preoperatif dönem:}

PEA cerrahisi için seçilen hasta grubu; cerrahi olarak ulaşılabilecek yerleşimde olan ve pulmoner vasküler rezistans (PVR) artışı ile sonuçlanan, bununla birlikte sekonder bir vaskülopatisi bulunmayan kronik pulmoner tromboembolik patolojisi olan hastalardı.

Preoperatif dönemde, hastalarda major organ disfonksiyonun olmaması, ventilasyon/perfüzyon sintigrafileri, kan testleri (hemogram, biyokimya, koagülasyon testleri, BNP), pulmoner fonksiyon testleri, oda havasındaki kan gazı değerleri, EKG, transözefagial ekokardiyografi (TÖE), koroner anjiyografi, abdominal USG, torasik BT, alt ekstremite venöz dopler USG, karotis ve vertebral arter dopler USG, 6 dakika yürüme testi ve kardiyak kateterizasyon bulguları değerlendirildi.

Cerrahiden önce taze donmuş plazma (TDP), eritrosit süspansiyonu (ES) ve trombosit süspansiyonu (PS) hazırlığı yapıldı.

KTEPH olgularında oksijenasyon rezervleri kısıtlı olduğu için, hastalara premedikasyon uygulanmadı.

\section{intraoperatif dönem:}

Supin pozisyonda yatan hastaya 5 derivasyonlu EKG, pulse oksimetre, radyal ya da brakiyal arterden invaziv basınç ölçümü, idrar output monitörizasyonu ve serebral oksimetre (NIRS) (INVOSTM, Somanetics/ Covidien, Boulder, CO, U.S.A) monitörize edildikten sonra bazal değerleri kaydedildi. Tüm hastalara hasta altı ısıtıcısı kullanıldı. Vücut ısı mönitörizasyonu özefajial probla sağlandı.

Anestezi indüksiyonu fentanyl $3 \mathrm{mcg} / \mathrm{kg}$, midazolam $0.08 \mathrm{mg} / \mathrm{kg}$, propofol $0,5-1 \mathrm{mcg} / \mathrm{kg}$ ve rokuronium $0.08 \mathrm{mg} / \mathrm{kg}$ ile kontrollü olarak sağlandı. Anestezi idamesinde fentanyl $0,5-1 \mathrm{mcg} / \mathrm{kg}$, midazolam 0.05 $\mathrm{mg} / \mathrm{kg}$, rocuronium $0.04 \mathrm{mg} / \mathrm{kg}$ dozlarında aralıklı intravenöz bolus olarak devam edilirken inhaler ajan tercih edilecekse sevoflurane \%0,5-\%1.2 kullanıldı. İndüksiyon sonrası endotrakeal entübasyonda 7,5-8 French (BIÇAKCILAR İstanbul, Türkiye) tüp yerleştirildi. Mekanik ventilasyon değerleri: $\mathrm{FiO}_{2} \% 100$, tidal volume (TV):6-8 ml/kg, solunum sayısı (f) $12-14 / \mathrm{dk}$, ekspirasyon sonrası pozitif basınç (PEEP) $6 \mathrm{cmH}_{2} \mathrm{O}$ olarak ayarlandı. Entübasyon sonrası bakılan kan gazı örneklerinde oksijenasyonuna göre $\mathrm{FiO}_{2}$ değeri \%70-100 arası yine ayarlanmıştır. Entübasyon sonrası hastaya TÖE probu yerleştirildi. Hastalara indüksiyon sonrası 20 ppm inhale nitrik oksid (iNO) başlandı. 
Sağ internal juguler venden 8,5 F santral venöz kateter (8.5 F venöz kateter Arrow International, USA) Seldinger yöntemi ile takıldı. Daha sonrasında pulmoner arter kateterizasyonu (ARROW 7.5 Fr 5 Lumen HANDS-OFF Infusion Port Thermodilution Catheter, International) uygulandı. Kardiyak output (KO) hemodilüsyon tekniği kullanılarak, mean pulmoner arter basınç (mPAB), Pulmoner kapiller oklizyon basınç (PKOB), kardiyak indeks (KI), pulmoner vasküler rezistans (PVR), sistemik vasküler rezistans (SVR) ölçümleri yapılarak kaydedildi.

Tüm hastalara femoral arter kateterizasyonu yapıldı. Hematokrit değeri $\geq 35$ olan hastalardan 1 ünite otolog kan alındı.

Sternotomi yapılıp KPB için kanüle edilen hastalara kanülasyon öncesi 300-400 iü/kg heparin uygulandı. Etkinleştirilmiş pıhtılaşma zamanı (ACT) düzeyi $>400$ olduğunda KPB başlatıldı. Hastalar $20^{\circ} \mathrm{C}$ dereceye soğutuldu. KPB için tercih edilen priming solusyonunda kolloid kullanıldı. Soğutulma süreci tamamlanan hastalara antegrad kardiyopleji kanülü konuldu. ilk kardiyopleji verilip kardiyak arrest sağlandıktan sonra total sirkülatuar arrest (TSA) geçildi. İlk (sağ) tarafın PEA işlemine başlandı. Bu dönem öncesi hastalara serebral koruma için $500 \mathrm{mg}$ pentotal, $1 \mathrm{gr}$ metilprednizolon, $40 \mathrm{mg}$ famotidin, $100 \mathrm{cc} \% 5^{\prime}$ lik mannitol ve $\mathrm{NaHCO}_{3}$ uygulandı. Illk taraf PEA tamamlanınca diğer tarafa aynı işlem uygulandı. TSA aralarında ve perfüzyon sonlandırıldığında hastalara rutin olarak bronkoskopi uygulanmıştır. TSA süresinde, cerrahi ekibe her $10 \mathrm{dk}$. için süre hatırlatıldı. Ayrıca hastaların NIRS değerlerinin \%30'un altında olması ve/veya giriş değerine göre $>\% 20$ 'dan fazla düşme olmasında TSA sonlandırıldı.

PEA işlemi bittikten sonra hastalar KPB ile ısıtılmaya başlandı. Hastalar ısıtılırken $35^{\circ} \mathrm{C}^{\prime}$ ye kadar ventilasyon ayarları $\mathrm{FiO}_{2} \% 30$, tidal volume (TV): $4 \mathrm{ml} / \mathrm{kg}$, solunum sayısı (f) 12-14/dk., PEEP $6 \mathrm{cmH}_{2} \mathrm{O}$ şeklinde ayarlandı. $35^{\circ} \mathrm{C}$ sonrası indüksiyon ayarlarına geri dönüldü. Kros klemp açıldıktan sonra hasta ısınırken akciğerler aspire edildi. Kan gazı kontrolü ile hemodinamik stabilite sağlanmış hastalarda KPB sonlandırıldı. Heparin nötralizasyonu için protamin uygulandı. Hemostaz sağlanıp sternum kapatıldıktan sonra tekrar termodilüsyon ölçümleri uygulandı.

\section{Postoperatif dönem:}

Hastalar iNO eşliğinde yoğun bakım ünitesine gönderildi. Yoğun bakım ünitesinde geniş monitorizasyon altında (EKG, invaziv basınç sistemik basınç, pulmoner basınç, idrar output, CVP, ISı monitörizasyonu) hastalar postoperatif 24 saat boyunca uyutuldu. Hastalara ekstübasyon öncesi bronkoskopi ile kanama kontrolü yapılmıştır. Postoperatif 1 . gün sonrası hemodinamisi stabil ve kangazı örneklemesi normal olan hastalar ekstübe edildi.

\section{Cerrahi Prosedür}

Hastalara median sternotomi uygulandı. Perikard açılıp bikaval kanülasyon sağlandıktan sonra antegrad kardiyopleji kanülü yerleştirildi. KPB'ta soğutulan hastaların ana pulmoner arterleri içerisine vent kanülleri yerleştirildi. Soğutma işlemi sonrası kardiyopleji ile arrest edilen kalpte sağ pulmoner arteriyotomi ve endarterektomi başlatıldı. Daha kansız bir alan sağlanması için TSA girildi. Sağ pulmoner endarterektomi bitirilince KPB desteği yine başlatıldı. Yapılan sağ pulmoner arteriyotomi kapatılıp, sol PEA için aynı işlemler yinelendi. Endarterektomi sonrası ısıtılan hastalar dekanüle edilerek sternotomileri kapatıldı.

\section{Istatiksel Analiz:}

Veriler, SPSS sürüm 26.0 paket programı (SPSS Inc. Bir IBM şirketi, Chicago, IL) kullanılarak analiz edildi. Sürekli parametreler ortalama \pm standart sapma olarak ifade edildi ve kategorik parametreler frekans (yüzde) olarak belirtildi.

\section{BULGULAR}

200 hastadan çalışmamızda Tablo 1'de hastaların demografik özellikleri sunulmuştur. Buna göre hastaların yaş ortalaması 50.8'dir. Kadın/erkek oranı ise 108/92'dir. Tablo 2'de hastaların intraoperatif dönemde değerlendirilen kangazı ölçümleri ve KO ölçümleri belirtilmiştir. Buna göre hastaların indüksiyon sonrası yapılan termodilüsyon ölçümlerinde $C O, P V R$ ve mPAB değerleri sırasıyla $4.4 \mathrm{l} / \mathrm{min}, 594 \mathrm{dyn} / \mathrm{s} / \mathrm{cm}^{-5}$, $40 \mathrm{mmHg}$ olarak saptanmıştır. Sternum kapatıldıktan sonra yapılan ölçümler ise yine aynı sırayla $6 \mathrm{l} / \mathrm{min}$, $241 \mathrm{dyn} / \mathrm{s} / \mathrm{cm}^{-5}$ ve $28 \mathrm{mmHg}$ 'dır. Tablo 3'te ise hastaların postoperatif dönem verileri sunulmuştur. Yoğun bakım (YBÜ) yatış süresi 4 gündür. Tablo 4 postoperatif komplikasyonların belirtildiği tablodur. 
Tablo 1. Demografik özellikler.

\begin{tabular}{|c|c|c|c|c|c|}
\hline Karakteristik özellikler & $\mathbf{n}$ & mean $\pm S D$ & Aralık & Minimum-Maksimum & $\%$ \\
\hline Yaş (yıl) & & $50,8 \pm 15,9$ & $23-85$ & & \\
\hline \multicolumn{6}{|l|}{ Cinsiyet } \\
\hline Erkek & 92 & & & & 46 \\
\hline Kadın & 108 & & & & 54 \\
\hline VKi $\left(m^{2}\right)$ & & $1,9 \pm 0,1$ & & & \\
\hline \multicolumn{6}{|l|}{ NYHA } \\
\hline II & 15 & & & & 7,5 \\
\hline III & 117 & & & & 58,5 \\
\hline IV & 68 & & & & 34 \\
\hline $\mathrm{FEV}_{1}(\%)$ & & $77,6 \pm 18,0$ & & $52-120$ & \\
\hline $\operatorname{FVC}^{1}(\%)$ & & $76,4 \pm 20,8$ & & $62-115$ & \\
\hline FEV1/FVC (\%) & & $83,4 \pm 15,8$ & & $52-122$ & \\
\hline $\mathrm{PABm}(\mathrm{mmHg})$ & & $40,6 \pm 14,4$ & & $19-69$ & \\
\hline $6 \mathrm{dk}$ yürüme testi (metre) & & $313,2 \pm 162,7$ & & $0-570$ & \\
\hline $\mathrm{EF}(\%)$ & & $63,7 \pm 5,2$ & & $42-67$ & \\
\hline TAPSE (mm) & & $19,9 \pm 3,6$ & & $8-24$ & \\
\hline
\end{tabular}

SD: Standart sapma, $F E V_{1}$ : 1. saniyedeki zorlu ekspiratuar volüm, FVC: Zorlu vital kapasite,

PABm: Ortalama pulmoner arter basıncı, TAPSE: Triküspit anülar ekskurjiyon, PVR: Vasküler rezistans,

EF: Ejeksiyon fraksiyonu, VKi: Vücut kitle indeksi, mm: Milimetre

Tablo 2. Intraoperatif özellikler.

mean $\pm S D$

$4,47 \pm 1,4$

Giriş (Indüksiyon Sonrası)

Kardiak output (I/min)

PVR (dyn $\left./ \mathrm{s} / \mathrm{cm}^{-5}\right)$

$\mathrm{PABm}(\mathrm{mmHg})$

GiRiş (İndüksiyon Sonrası)

$\mathrm{Ph}$

$\mathrm{PaCO}_{2}(\mathrm{mmHg})$

$\mathrm{PaO}_{2}(\mathrm{mmHg})$

Laktat (mmol/L)

Çıkış (Sternum Kapatıldıktan sonra)

Kardiak output (I/min)

PVR (dyn $\left./ \mathrm{s} / \mathrm{cm}^{-5}\right)$

$\mathrm{PABm}(\mathrm{mmHg})$

TSA (dk)

AKK (dk)

KPB zamanı (dk)
$594,5 \pm 369,2$

$40,6 \pm 14,4$

$7,34 \pm 0,08$

$39,9 \pm 7,9$

$182 \pm 51,7$

$1,8 \pm 0,5$

$6,0 \pm 1,9$

$241,3 \pm 224,1$

$28,5 \pm 9,5$

$23,1 \pm 9,5$

$38,8 \pm 34,7$

$207,5 \pm 37,0$
$1,72-5,9$

Minimum-Maksimum

76-2051

19-69

2,43-11

46-2153

15-66

3-56

2-309

150-396

PVR: Pulmoner vasküler rezistans; PABm: Ortalama pulmoner arter basıncı, PaCO : parsiyel karbondioksit miktarı,

$\mathrm{PaO}_{2}$ : parsiyel oksijen miktarı, KPB: Kardiyopulomner baypas; TSA:Total sirkülauar arrest; AKK: Aortik kros klemp süresi

\section{Tablo 4. Komplikasyonlar.}

\section{Tablo 3. Postoperatif dönem özellikleri.}

\begin{tabular}{lcc} 
& mean \pm SD & $\begin{array}{c}\text { Minimum- } \\
\text { Maksimum }\end{array}$ \\
\hline Ventilasyon süresi (gün) & $1,3 \pm 0,93$ & $1-6$ \\
Ybü kalış süresi (gün) & $4,1 \pm 3,4$ & $2-31$ \\
Hastane yatış zamanı (gün) & $11,6 \pm 5,9$ & $7-45$
\end{tabular}

Ybü: Yoğun bakım ünitesi

\begin{tabular}{lcc} 
& $\mathbf{n}$ & $\%$ \\
\hline Rezidüel pulmoner hipertansiyon & 42 & 21 \\
Reperfüzyon pulmoner ödem & 20 & 10 \\
Pulmoner hemoraji & 8 & 4 \\
Revizyon & 13 & 6,4 \\
Renal yetmezlik & 3 & 1,6 \\
Nörolojik komplikasyon & 12 & 6,2 \\
Aritmi & 5 & 2,4 \\
ECMO & 3 & 1,6 \\
Bronşiyal Bloker ihtiyacl & 5 & 2,5 \\
Erken mortalite & 11 & 5,6 \\
\hline
\end{tabular}


Hasta grubumuzda \%21 oranında rezidüel pulmoner hipertansiyon, $\% 10$ oranında reperfüzyon pulmoner ödem ve \%4 oranında ise pulmoner kanama olmuştur.

\section{TARTIŞMA}

KTEPH akut pulmoner embolizm olgularının \%4'ünde gelişebilen ve pulmoner endarterektomi ile tedavi edildiği bilinen bir kronik pulmoner hipertansiyon nedenidir ${ }^{[4]}$. Ülkemizde KTEPH insidansı \%4.6 olarak verilmiştir ${ }^{[5]}$. Pulmoner hipertansiyon semptomları taşıyan hastalar mutlaka değerlendirilmeli ve pulmoner arter basıncı yüksek (PABm $\geq 25 \mathrm{mmHg}$, PKOB $<15 \mathrm{mmHg}$ ve PVR $>2$ wood) olan, pulmoner arterlerde değişik seviyelerde birden fazla tıkayıcı lezyon bulunan hastalara KTEPH tanısı düşünülmelidir ${ }^{[6]}$. Tanıda altın standart pulmoner ventilasyon perfüzyon sintigrafisidir. Ameliyat kararı alınırken toraks bilgisayarlı tomografi ve pulmoner anjiyografiye gereksinim duyulur ${ }^{[7]}$.

Çalışmamızdaki hastalara premedikasyon uygulanmamıştır. Çünkü hipoksi, hiperkarbi ve hipotansiyon pulmoner vasküler rezistansı artırabileceğinden bu durumlardan kaçınılmalıdır. Hipotansiyon aynı zamanda sağ ventrikül perfüzyonunu bozacağından düşük doz alfa agonist veya dopamin hemodinamik stabiliteyi korumada yararlı olmaktadır ${ }^{[8]}$. Bu nedenle PEA ameliyatlarında indüksiyon aşaması oldukça önemlidir.

KTEPH sağ kalp yetmezliği, paradoksal interventriküler hareket, triküsit yetmezliği ve hepatik konjesyon gibi birçok patolojiyi farklı derecelerde meydana getirebilir ${ }^{[9,10]}$. PEA anestezisinde temel prosedür açık kalp cerrahisine benzese de etkili bir sağ kalp monütorizasyonun yapılması ve takibi oldukça önemlidir. Sağ kalp kateterizasyonunda KO, Ki, PAs $>50$ $\mathrm{mmHg}$ PVR $>600$ dynes-sec- $\mathrm{cm}^{-5}$ ve sağ ventrikül diastolik basınç $>14 \mathrm{mmHg}$ olması ciddi sağ ventrikül yetmezliği olduğunu gösterir ${ }^{[2]}$. İntraoperatif TÖE PEA cerrahisinde sağ ventriküler disfonksiyon, bölgesel duvar hasarı, hemodinamik insitabilitenin nedenin belirlenlenmesi, hastadaki volüm derecesinin bilinmesi, triküspit yetmezliği, patent foramen ovale (PFO) gibi yapıların değerlendirilmesinde, intrakardiyak trombüs gibi yapıların belirlenmesinde oldukça önemli bir monitörizasyon yöntemidir ${ }^{[11]}$. PEA ameli- yatlarında serebral perfüzyonun monitörizasyonu oldukça önemlidir ${ }^{[12]}$. Bu amaçla hastalarda rutin olarak serebral oksimetre kullanılmıştır. Özellikle pulmoner endarterektominin yapıldığı dönemde uygulanan TSA sırasında beyin oksijnasyonunun yakından takip edilmesi gerekir. PEA cerrahisinde TSA dönemlerinde uç organ hasarının önlenmesi amacı ile derin hipotermi uygulanmaktadır ${ }^{[7]}$. Derin hipotermiye rağmen NIRS değerlerinde inisyal serebral oksijen saturasyonun $\geq \% 30$ azaldığında hastalarda postoperatif nörokognitif bozukluk oluşmasını engellemek amacıyla TSA'e son verip perfüzyona geçilmelidir. Aynı nedenle genellikle TSA sürelerinin $10 \mathrm{dk} . ' \mathrm{y}$ । aşmaması önerilmektedir.

Yapılan çalışmalarda, açık kalp cerrahisi geçiren hastalarda \%40 oksijen saturasyonunun altında ve 10 dk'dan fazla serebral hipoksisi olan hastalarda nörokognitif disfonksiyon daha fazla gözlenmiştir ${ }^{[13]}$.

Derin hipotermi sebebi ile hastalarda üst ekstremite arteriyal sistemde oluşabilecek vazospazm dolayısıyla arteryal monitörizasyonun daha güvenli bir şekilde takip edilebilmesi için indüksiyon sonrası femoral arter kateterizasyonu yapılması ve hemodinamik takibin bu yolla devam ettirilmesi daha güvenli olacaktır.

KPB'tan ayrılma sürecinde sağ, sol veya her iki ventrikülün desteklenmesi amacıyla inotropik ajan kullanımına gereksinim duyulabilir ${ }^{[8]}$. Bu dönemde TÖE ve KO ölçümleri önemlidir.

PEA cerrahisinde en sık görülen major komplikasyonlar rezidüel pulmoner hipertansiyon (\%10-\%35), reperfüzyon pulmoner ödem (\%10-15) ve pulmoner hemorajidir $(\% 5,5)^{[14-20]}$. Serimizdeki hastalarda rezidüel pulmoner hipertansiyon $\% 21$, reperfüzyon ödem $\% 10$ ve pulmonerhemoraji ise $\% 4$ oranında görülmüştür. Literatürde mortaliteyi etkileyen en önemli komplikasyon ise rezidüel pulmoner hipertansiyon (>500 dyn.s. $\mathrm{cm}^{5}$ ) olarak belirtilmiştir ${ }^{[21]}$. PEA cerrahisinde erken mortalite oranı merkezlerin deneyimlerine göre değişmektedir. Bu nedenle literatürde bu oran $\% 4$ ile $\% 23$ arasında değişen oranlarda belirtilmiştir ${ }^{[9,22]}$. Hasta grubumuzdaki erken mortalite oranı $\% 5.6$ olarak belirlenmiştir.

Merkezimizde, literatüre uygun olarak en sık karşılaş- 
tığımız komplikasyon rezidüel pulmoner hipertansiyondur. Persistan pulmoner hipertansiyon distal trombüsün yetersiz temizlenmesi veya operabl proksimal hastalıkla konkomitant küçük damar hastalığı olan olgularda daha sık görülmektedir ${ }^{[23,24]}$. Rezidüel pulmoner hipertansiyon gelişen hastalarda hedef tedavi gelişebilecek sağ kalp yetmezliğine yönelik olmalıdır.

Tüm hastalarımızda 20 ppm iNO kullanılması rutin bir uygulamadır. Ayrıca pulmoner vazodilatör ajan olarak ilioprost ve sağ kalp yetmezliğine yönelik milrinon ve diğer inotropik ajanlar kullanılabilmektedir ${ }^{[25,26]}$. Hastalarımızda intraoperatif dönemde hemodinamik stabiliteyi ve uygun miktarda hidrasyon desteğini sağlayabilmek için CVP ve TÖE monitörizasyonu kullandık. Hastalardaki KPB sonrası kalp atım hızını yüksek ve sistemik tansiyonu istenilen sınırlarda tutabilmek için inotrop gereksiniminde ilk seçeneğimiz dobutamin sonrasında ise norepinefrin olmuştur. Tüm bu medikal tedavilere rağmen üstesinden gelinemeyen kardiyak yetmezlik durumlarında santral veno-arteriyal ECMO gereksinimi olabilmektedir.

Reperfüzyon pulmoner ödem bir diğer sık görülen PEA cerrahisi komplikasyonudur. Perioperatif 48 saat içerisinde ortaya çıkabilen ve revaskülerize edilen pulmoner yatakta pulmoner hiperemi ile karaterize, akut akciğer hasarına benzeyen ve çeşitli derecelerde şiddeti değişebilen bir komplikasyondur ${ }^{[27,28]}$. Bu durumda yüksek PEEP $\left(8-10 \mathrm{cmH}_{2} \mathrm{O}\right)$, tidal volüm $<6 \mathrm{ml} / \mathrm{kg}$, inspirasyon ekspirasyon oranı $1 / 3$, peak inspirasyon basıncı $\leq 18 \mathrm{mmHg}$ olacak şekilde ventilasyon stratejisi uygulanmalıdır. Negatif SIVI dengesi ve diüretik tedaviye ek olarak reperfüzyon sonrası serbest oksijen radikallerinin ve diğer inflamatuar ajanların etkisini azaltmak amacıyla tüm hastalara metilprednizolon ve iNO tedavisi rutin olarak uygulanmaktadır. Ayrıca serbest oksijen radikallerinin oluşumunu önlemek amacıyla yüksek $\mathrm{FiO}_{2}$ seviyesinden kaçınılmalıdır. Ödemin fazla olduğu ve kan/gaz değişiminin yetersiz olduğu durumlarda santral veno-arteriyal ECMO gereksinimi ortaya çıkabilmektedir.

Pulmoner hemoraji PEA cerrahisinde daha az karşılaşılmasına rağmen baş edilmesi en güç olan komplikasyondur. Kanama odağının bulunabilmesi ve tedavi edilebilmesinde bronkoskopinin rolü büyüktür.

Bronkoskopi ile yeri saptanan kanama odağı cerrahi olarak onarılamaz ise bronkoskopi eşliğinde kanamanın olduğu segmentlere endobronşial bloker yerleştirerek diğer akciğer sahaları izole edilir.

Eğer kanama lober kaynaklı ise endobronşial blokerler ile kanamalı akciğer lobu izole edilebilir. Masif kanamalarda ise çift lümenli endobronşial tüp uygulanarak karşı akciğer izolasyonu sağlanır. Endobronşial blokör kullanarak yapılan izolasyonların amacı sağlam akciğer sahalarının kan ile dolarak gaz değişiminin daha da bozulmasının önlenmesidir ${ }^{[2,29]}$. Buna ek olarak, konservatif tedavide PEEP uygulaması heparinin antagonize edilmesi, koagülopatilerin düzeltilmesi ve adrenalin gibi topikal vazokonstriktörler ile yıkama yapılarak küçük kanamalar kontrol altına alınabilir. Bu uygulamaların yetersizliğinde ise cerrahi olarak pulmoner arter eksplore edilerek klemplenebilir. Hemodinaminin korunamadığı ve kan gaz değişiminin yetersiz olduğu olgularda ise santralvenoarteriyal ECMO kullanılmalıdır.

Postoperatif dönemde hastalar, kan-gaz değişimi ve hemodinamik stabilizasyonları sağlanarak 24 saat uyutulmalıdır. Bu amaçla ekstübasyon öncesi hastalardalardaki pulmoner hemoraji durumu bronkoskopi ile gösterilmelidir. Yoğun bakımda kullanılan iNO tedavisi rebound pulmoner hipertansiyon gelişme riskinin ortadan kaldırılması amacıyla kademeli olarak azaltılarak sonlandırımalıdır. Uygun hastaların ise postoperatif 24 saat sonrası $\mathrm{FiO}_{2}$ ve $\mathrm{PEEP}$ düzeyi azaltılarak ekstübasyonu planlanmalıdır. ECMO desteği ile YBÜ'ye alınan hastalar yakın takibi yapılmalıdır.

PEA cerrahisinde dünyada deneyimli merkez sayısı oldukça azdır ve PEA ameliyatlarında anestezi yönetimi; derin hipotermi, TSA, sağ ventrikül yetmezliğinin tedavisi gibi bir çok komplike klinik durumu kapsamaktadır.

Çalışmamızdaki amacımız, tüm bu klinik zorlukları barındıran, komplikasyonlar karşısındaki tedavi seçeneklerini belirten daha efektif bir anestezi yönetimini literatüre sunabilmektir. Bu nedenle PEA cerrahisinin daha deneyimli ve multidsipliner merkezlerde uygulanması gerektiği düşüncesindeyiz. 


\section{KAYNAKLAR}

1. Jenkins D, Madani M, Fadel E, D’Armini MA, Mayer E. Pulmonary endarterectomy in the management of chronic thromboembolic pulmonary hypertension. Eur Respir Rev. 2017;26(143):160111. https://doi.org/10.1183/16000617.0111-2016

2. Banks DA, Pretorius GVD, Kerr KM, Manecke GR. Pulmonary Endarterectomy: Part II. Operation, anesthetic management, and postoperative care. Semin Cardiothorac Vasc Anesth. 2014;18(4):331-40. https://doi.org/10.1177/1089253214537688

3. Yıldızeli ŞO, Kepez A, Taş S, Yanartaş M, Durusoy AF, Erkılınç A ve ark. Pulmonary endarterectomy for patients with chronic thromboembolic disease. Anatol J Cardiol. 2018;19(4):273-8. https://doi.org/10.14744/AnatolJCardiol.2018.37929

4. McLaughlin VV, Shah SJ, Souza R, Humbert M. Management of pulmonary arterial hypertension. J Am Coll Cardiol. 2015;65(18):1976-97. https://doi.org/10.1016/j.jacc.2015.03.540

5. Korkmaz A, Ozlu T, Ozsu S, Kazaz Z, Bulbul Y. Long-term outcomes in acute pulmonary thromboembolism: The incidence of chronic thromboembolic pulmonary hypertension and associated risk factors. Clin Appl Thromb Hemost. 2012;18:218-8. https://doi.org/10.1177/1076029611431956

6. Galiè N, Humbert M, Vachiery J-L, Gibbs S, Lang I, Torbicki $A$ et al. 2015 ESC/ERS Guidelines for the diagnosis and treatment of pulmonary hypertension: The Joint Task Force for the Diagnosis and Treatment of Pulmonary Hypertension of the European Society of Cardiology (ESC) and the European Respiratory Society (ERS): Endorsed by: Association for European Paediatric and Congenital Cardiology (AEPC), International Society for Heart and Lung Transplantation (ISHLT). Eur Heart J 2016;37(1):67-119.

https://doi.org/10.1093/eurheartj/ehv317

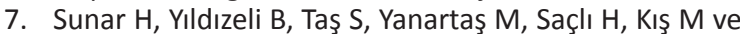
ark. Pulmonary endarterectomy in chronic thromboembolic pulmonary hypertension. Türk Göğüs Kalp Damar Cerrahisi Dergisi 2013;21(1):7-13. https://doi.org/10.5606/tgkdc.dergisi.2013.7625

8. Valchanov K, Vuylsteke A. Pulmonary endarterectomy. Eur J Anaesthesiol. 2006;23(10):815-23. https://doi.org/10.1017/S0265021506001268

9. Thistlethwaite PA, Kemp A, Du L, Madani MM, Jamieson SW. Outcomes of pulmonary endarterectomy for treatment of extreme thromboembolic pulmonary hypertension. J Thorac Cardiovasc Surg. 2006;131(2):30713.

https://doi.org/10.1016/j.jtcvs.2005.07.033

10. Madani MM, Auger WR, Pretorius V, Sakakibara N, Kerr KM, Kim NH et al. Pulmonary endarterectomy: recent changes in a single institution's experience of more than 2,700 patients. Ann Thorac Surg. 2012;94(1):97-103.

https://doi.org/10.1016/j.athoracsur.2012.04.004

11. Tomasi R, Betz D, Schlager S, Kammerer T, Hoechter DJ, Weig T et al. Intraoperative Anesthetic Management of LungTransplantation: Center Specific Practices and Geographic and Centers Size Differences. J Cardiothorac Vasc Anesth. 2018;32(1):62-9. https://doi.org/10.1053/j.jvca.2017.05.025

12. Edmonds HL Jr, Ganzel BL, Austin EH 3rd. Cerebral oximetry for cardiac and vascular surgery. Semin Cardiothorac Vasc Anesth. 2004;8(2):147-66. https://doi.org/10.1177/108925320400800208

13. Yao FS, Tseng CC, Ho CY, Levin SK, Illner P. Cerebral oxygen desaturation is associated with early postoperative neuropsychological dysfunction in patients undergoing cardiac surgery. J Cardiothorac Vasc Anesth. 2004;18(5):552-8. https://doi.org/10.1053/j.jvca.2004.07.007

14. Bonderman D, Skoro-Sajer N, Jakowitsch J, Adlbrecht C, Dunkler D, Taghavi S et al. Predictors of outcome in chronic thromboembolic pulmonary hypertension. Circulation 2007;115(16):2153-8. https://doi.org/10.1161/CIRCULATIONAHA.106.661041

15. Thistlethwaite PA, Madani MM, Kemp AD, Hartley M, Auger WR, Jamieson SW. Venovenous extracorporeal life support after pulmonary endarterectomy: indications, techniques, and outcomes. Ann Thorac Surg. 2006;82(6):2139-45. https://doi.org/10.1016/j.athoracsur.2006.07.020

16. Fedullo PF, Kerr KM, Auger WR, jamieson SE, Kapelanski DP. Chronic thromboembolic pulmonary hypertension. Semin Respir Crit Care Med 2000; 21:563-574

17. Mayer E, Jenkins D, Lindner J, D'Armini A, Kloek J, Meyns B et al. Surgical management and outcome of patients with chronic thromboembolic pulmonary hypertension: results from an international prospective registry. J Thorac Cardiovasc Surg. 2011;141(3):70210. https://doi.org/10.1016/j.jtcvs.2010.11.024

18. Mares P, Gilbert TB, Tschernko EM, Hiesmayr M, Muhm M, Herneth $A$, et al. Pulmonary artery thromboendarterectomy: a comparison of two different postoperative treatment strategies. Anesth Analg. 2000;90(2):267-73. https://doi.org/10.1097/00000539-200002000-00006

19. lyengar RMN, Hegde D, Chattuparambil B, Gupta R, Patil L. Postoperative management of pulmonary endarterectomy and outcome. Ann Card Anaesth. 2010;13(1):22-7. https://doi.org/10.4103/0971-9784.58830

20. Opitz I, Ulrich S. Chronic thromboembolic pulmonary hypertension. Swiss Med Wkly 2018;148:w14702. https://doi.org/10.4414/smw.2018.14702

21. Madani MM. Surgical treatment of chronic thromboembolic pulmonary hypertension: Pulmonary thromboendarterectomy. Methodist Debakey Cardiovasc J 2016;12(4):213-18.

https://doi.org/10.14797/mdcj-12-4-213

22. Wittine LM, Auger WR. Chronic thromboembolic pulmonary hypertension. Curr Treat Options Cardiovasc Med. 2010;12(2):131-41. https://doi.org/10.1007/s11936-010-0062-0

23. Jenkins D. Pulmonary endarterectomy: the potentially curative treatment for patients with chronic thromboembolic pulmonary hypertension. Eur Respir Rev 2015;24(136):263-71. https://doi.org/10.1183/16000617.00000815

24. Kim NHS, Fesler P, Channick RN, Knowlton KU, BenYehuda O, Lee SH et al. Preoperative partitioning of pulmonary vascular resistance correlates with early outcome after thromboendarterectomy for chronic 
thromboembolic pulmonary hypertension. Circulation 2004;109(1):18-22.

https://doi.org/10.1161/01.CIR.0000111841.28126.D4

25. Kramm T, Eberle B, Guth S, Mayer E. Inhaled diloprost to control residual pulmonary hypertension following pulmonary endarterectomy. Eur J Cardiothorac Surg 2005;28(6):882-8

https://doi.org/10.1016/j.ejcts.2005.09.007

26. Kramm T, Eberle B, Krummenauer F, Guth S, Oelert H, Mayer E. Inhaled diloprost in patients with chronic thromboembolic pulmonary hypertension: effects before and after pulmonary thromboendarterectomy. Ann Thorac Surg. 2003;76(3):711-8.

https://doi.org/10.1016/S0003-4975(03)00728-8
27. Lee KC, Cho YL, Lee SY. Reperfusion pulmonary edema after pulmonary endarterectomy. Acta Anaesthesiol Sin 2001;39(2):97-101.

28. Loubser PG. CASE 3--1998. Pulmonary reperfusion edema associated with pulmonary thromboendarterectomy. J Cardiothorac Vasc Anesth. 1998;12(3): 353-7.

https://doi.org/10.1016/S1053-0770(98)90021-0

29. Olgun Yıldızeli Ş, Erkılınç A, Yanartaş M, Taş S, Sunar H, Gürcü E, Yıldızeli B. Perioperative management of massive pulmonary hemorrhage after pulmonary endarterectomy. Turk Gogus Kalp Damar Cerrahisi Derg. 2018 Jul 3;26(3):429-435.

https://doi.org/ 10.5606/tgkdc.dergisi.2018.15404. 